\title{
A Comparative Study of Assessing Software Reliability using Spc: an Mmle Approach
}

\author{
Bandla.Srinivasa Rao \\ Department of Computer \\ Science and Engineering \\ VRS \& YRN College of \\ Engineering and Technology \\ Chirala, India
}

\author{
R.Satya Prasad \\ Phd,Department of Computer \\ Science and Engineering \\ Acharya Nagarjuna \\ University \\ Guntur, India
}

\author{
K. Ramchand H Rao \\ Phd,Department of Computer \\ Science and Engineering \\ A.S.N. Womens Eng.College \\ Tenali, India
}

\begin{abstract}
The Modified Maximum Likelihood Estimation (MMLE) of the parameters of Exponential and Half Logistic distributions are considered and compared. An analytical approximation is used instead of linear approximation for a function which appears in Maximum Likelihood equation. These estimates are shown to perform better, in the sense of simplicity of calculation than the one based on linear approximation for the same function. In this paper we identified the MMLE method of estimations and associated results using Half Logistic Distribution and Exponential Distribution are similar. These estimates are used in SPC to find the control limits to predict the software reliability. A comparison of software reliability using Statistical Process Control for a small sample is also presented
\end{abstract}

\section{Key words}

Software Reliability, Statistical Process Control, Modified Maximum Likelihood, Exponential Distribution, Half Logistic Distribution, Control Limits, NHPP

\section{INTRODUCTION}

When the data is in the form of inter failure times, we will try to estimate the parameters of an NHPP model based on exponential [16] and Half Logistic distributions [17]. Let $\mathrm{N}(\mathrm{t})$ be an NHPP defined as

$\mathrm{p}[\mathrm{N}(\mathrm{t})]=\frac{\left.[m(t)]^{y}\right)}{y !} e^{-m(t)}, \mathrm{y}=0,1,2, \ldots \ldots \mathrm{n}$

Here $m(t)$ are the mean value function of Exponential and Half Logistic Distributions respectively and is given by

$\begin{array}{ll}m(t)=a\left(1-e^{-b t}\right) & 1.1 \\ m(t)=\frac{a\left(1-e^{-b t}\right)}{a\left(1+e^{-b t}\right)} & 1.2\end{array}$

The corresponding intensity functions of the process is given by

$$
\begin{array}{ll}
\lambda(t)=b(a-m(t)) & 1.3 \\
\lambda(t)=\frac{2 a b e^{-b t}}{\left(1+e^{-b t}\right)^{2}} & 1.4
\end{array}
$$

In the above equations the constants ' $a$ ' and ' $b$ ' are called unknown parameters of the models. In order to assess the software reliability ' $a$ ' and 'b' are to be known or they are estimated by classical method of estimation namely Maximum Likelihood estimation (MLE) and it is an iterative solution of ML equation. Approximation and modification to the Maximum Likelihood (ML) Method of estimation in certain distributions to overcome interactive solution of ML equation for the parameter were suggested by many authors [18][12][15][4[19][20][21].Tiku et. al. obtained modified Maximum Likelihood (MML) Estimation by making linear approximation(s) to certain function(s) in ML equations of the parameters of exponential, Half Logistic distributions. R. Satya Prasad, Bandla Srinivasa Rao, RRL Kantam [16] Studied software reliability using MML estimation for Exponential Distribution. R. Satya Prasad, K Ramchand H Rao, RRL Kantam studied reliability of the software using MML estimation for Half Logistic Distribution[17]. Here, we used two popular distributions, exponential and Half Logistic for parameter estimation to asses the software reliability using SPC [8][10]

\section{MML ESTIMATION FOR EXPONENTIAL AND HALF LOGISTIC DISTRIBUTIONS}

$\begin{array}{lcr}\text { 2.1Modified } & \text { Maximum } & \text { Likelihood } \\ \text { Estimation } & \text { Using } & \text { Exponential }\end{array}$

\section{Distribution}

Suppose we have ' $n$ ' time instants at which the first, second, third..., $\mathrm{n}^{\text {th }}$ failures of software are experienced. In other words if $s_{k}$ is the total time to the $\mathrm{k}^{\text {th }}$ failure, $s_{k}$ is an observation of random variable $s_{k}$ and ' $n$ ' such failures are successively recorded. The joint probability of such failure time realizations $s_{1}, s_{2}, s_{3}, \ldots s_{n}$ is

$L=e^{-m\left(s_{n}\right) \cdot} \prod_{k=1}^{n} \lambda\left(s_{k}\right)$

The simplified form for log likelihood equation of Exponential Distribution is [1]

$\sum_{k=1}^{n} S_{\mathrm{k}} a^{n-k} \frac{n}{b}-a n s_{n} e^{-b s_{n}}=0$ (2.1.2)

Let us approximate the following expressions in the L.H.S of equation (2.1.2) by linear functions in the neighborhoods of the corresponding variables.

$\frac{s_{n} e^{-b s_{n}}}{1-e^{-b s_{n}}}=m \mathrm{~S}_{\mathrm{n}}+c, \mathrm{n}=1,2, \ldots \ldots \mathrm{n}$.

Where $S_{n}$ is the slope and ' $c$ ' is the intercepts in equation (2.1.3) is to be suitably found. With such values equation (2.1.3) when used in equation (2.1.2) would give an approximate MLE for ' $b$ ' as

$$
\begin{aligned}
& \hat{\mathrm{b}}=1+\frac{1}{\left(m S_{\mathrm{n}}+\mathrm{c}\right)+\overline{\mathrm{s}}} \\
& \text { where } \overline{\mathrm{s}}=\sum_{\mathrm{k}=1}^{\mathrm{n}} \frac{S_{\mathrm{k}}}{\mathrm{n}}
\end{aligned}
$$

We suggest the following method to get the slopes and intercepts in the R.H.S of equations (2.1.3).

$$
\begin{aligned}
& F(z)=\frac{n}{n+1} \\
& \mathrm{~F}\left(\mathrm{Z}^{\prime}\right)=p-\sqrt{\frac{p q}{n}} \\
& \mathrm{~F}\left(\mathrm{Z}^{\prime \prime}\right)=p+\sqrt{\frac{p q}{n}}
\end{aligned}
$$

Given a natural number ' $\mathrm{n}$ ' we can get the values of $\mathrm{Z}$ ' and Z"by inverting the above equations through the function $\mathrm{F}(\mathrm{z})$ the L.H.S of equation (2.1.3) we get

$$
\begin{aligned}
& m=\frac{\left(\frac{z^{\prime} e^{-z^{\prime}}}{1-e^{-z^{\prime}}}\right)-\left(\frac{z^{\prime \prime} e^{-z^{\prime \prime}}}{1-e^{-z^{\prime \prime}}}\right)}{z^{\prime}-z^{\prime \prime}} \\
& c=\frac{z^{\prime} e^{-z^{\prime}}}{1-e^{-z^{\prime}}}-m z^{\prime}
\end{aligned}
$$

It can be seen that the evaluation of $S_{n}$, 'c' are based on only a specified natural number ' $\mathrm{n}$ ' and can be computed free from any data. Given the data observations and sample size using these values along with the sample data in equation (2.1.8) (2.2.7) we get an approximate MLE of ' $b$ '.

$a=\frac{n}{1-e^{-b s_{n}}}$

Equation (2.1.10) gives approximate MLE of 'a'. 


\subsection{Modified Maximum Likelihood Estimation Using Half Logistic Distribution}

The simplified form of log likelihood equation of HLD is [2]

\section{(2.2.1)}

Let us approximate the following expressions in the L.H.S of equation (2.1) by linear functions in the neighborhoods of the corresponding variables.

$$
\begin{aligned}
& \frac{z_{k} \cdot e^{-z_{k}}}{1+e^{-z_{k}}}=\alpha_{k}+\beta_{k} \cdot z_{k}, k=1,2, \ldots ., n . \\
& \frac{z_{n} \cdot e^{-z_{n}}}{1-e^{-2 z_{n}}}=\gamma_{n}+\delta_{n} \cdot z_{n}
\end{aligned}
$$

Where the slopes $\alpha_{k}, \gamma_{n}$ and intercepts $\beta_{\mathrm{k}}, \delta_{\mathrm{n}}$ in equations (2.2.2) and (2.2.3) are to be suitably found. With such values equations (2.2.2) and (2.2.3) when used in equation (2.2.1) would give an approximate MLE for ' $b$ ' as

$$
\hat{b}=\frac{n+2 \sum_{k=1}^{n} \alpha_{k}-2 n \gamma_{n}}{\sum_{k=1}^{n} s_{k}-2 \sum_{k=1}^{n} \beta_{k} \cdot s_{k}+2 n \delta_{n} s_{n}}
$$

We suggest following method to get the slopes and intercepts in the R.H.S of equations (2.2.2) and (2.2.3)

Let $F(z)=\frac{1-e^{-z}}{1+e^{-z}}$

$$
\begin{aligned}
& p_{i}=\frac{i}{n+1}, i=1,2, \ldots, n \\
& F\left(u_{i}^{\prime}\right)=p_{i}-\sqrt{\frac{p_{i}\left(1-p_{i}\right)}{n}} \\
& F\left(u_{i}^{\prime \prime}\right)=p_{i}+\sqrt{\frac{p_{i}\left(1-p_{i}\right)}{n}}
\end{aligned}
$$

Given a natural number ' $n$ ' we can get the values of $u_{i}^{\prime}$ and $u_{i}^{\prime \prime} \quad$ by inverting the above equations through the function $\mathrm{F}(\mathrm{z})$. If $\mathrm{G}(),. \mathrm{H}($.$) are the symbols for the$ L.H.S of equations (2.2.2) and (2.2.3) we get

$$
\begin{aligned}
& \beta_{k}=\frac{G\left(u_{k}^{\prime \prime}\right)-G\left(u_{k}^{\prime}\right)}{u_{k}^{\prime \prime}-u_{k}^{\prime}}, k=1,2, \ldots, n \\
& \alpha_{k}=G\left(u_{k}^{\prime}\right)-\beta_{k} \cdot u_{k}^{\prime}, k=1,2, \ldots, n \\
& \delta_{n}=\frac{\mathrm{H}\left(\mathrm{u}_{\mathrm{n}}^{\prime \prime}\right)-\mathrm{H}\left(\mathrm{u}_{\mathrm{n}}^{\prime}\right)}{\mathrm{u}_{\mathrm{n}}^{\prime \prime}-\mathrm{u}_{\mathrm{n}}^{\prime}} \\
& \gamma_{n}=\mathrm{H}\left(\mathrm{u}_{\mathrm{n}}^{\prime}\right)-\delta_{n} \cdot \mathrm{u}_{\mathrm{n}}^{\prime} .
\end{aligned}
$$

Given the data observations and sample size using these values along the sample data in equation (2.2.4) we get an approximation MLE of "b".

$a=n\left[\frac{1+e^{-b s_{n}}}{1-e^{-b s_{n}}}\right]$

Equation (2.2.5) gives approximate MLE of ' $a$ '.

\subsection{Parameter Estimation using Inter Failure Times Data}

Based on the time between failures data give in Table-1, we compute the two unknown parameters of ' $\hat{a}$ ' and ' $\hat{b}$.

Table -1: Cumulative Inter failures Time Data [11]

\begin{tabular}{|c|c|c|c|c|c|}
\hline $\begin{array}{l}\text { Failure } \\
\text { number }\end{array}$ & $\begin{array}{l}\text { Time between } \\
\text { Failure } \\
\text { (cumulative) }\end{array}$ & Failure number & $\begin{array}{l}\text { Time between } \\
\text { Failure } \\
\text { (hrs) } \\
\text { (cumulative) }\end{array}$ & $\begin{array}{l}\text { Failure number } \\
\text { Time }\end{array}$ & $\begin{array}{l}\text { Fetween } \\
\text { Failure } \\
\text { (hrs) }\end{array}$ \\
\hline 1 & 30.02 & 11 & 115.34 & 21 & 256.81 \\
2 & 31.46 & 12 & 121.57 & 22 & 273.88 \\
3 & 53.93 & 13 & 124.97 & 23 & 277.87 \\
4 & 55.29 & 14 & 134.07 & 24 & 453.93 \\
5 & 58.72 & 15 & 136.25 & 25 & 535 \\
6 & 71.92 & 16 & 151.78 & 26 & 537.27 \\
7 & 77.07 & 17 & 177.5 & 27 & 552.9 \\
8 & 80.9 & 18 & 180.29 & 28 & 673.68 \\
9 & 101.9 & 19 & 182.21 & 29 & 704.49 \\
10 & 114.87 & 20 & 186.34 & 30 & 738.68 \\
\hline
\end{tabular}

The ' $\hat{a}$ ' and ' $\hat{b}$ ' are Modified Maximum Likelihood Estimates (MMLEs) of parameters and the values can be computed using analytical method. The parameters values are shown in Table-2

Table -2: Parameter values of Exponential and Half Logistic Distributions

\begin{tabular}{|c|c|c|}
\hline Name of the Distribution & $\hat{a}$ & $\hat{\boldsymbol{b}}$ \\
\hline Exponential & 33.396342 & 0.003962 \\
\hline Half Logistic & 31.27686 & 0.00433 \\
\hline
\end{tabular}

\section{NUMERICAL ILLUSTRATION}

The control limits are used to find whether the software process is in control or not by placing the points in chart shown in figure-1.and figure-2. A point below the control limit $m\left(t_{L}\right)$ indicates an alarming signal. A point above the control limit $m\left(t_{u}\right)$ indicates better quality. If the points are falling within the control limits it indicates the software process is in stable [13].
The procedure of a failures control chart for failure software process will be illustrated with an example here. Table 2 shows the time between failures (cumulative) in hours, corresponding $\mathrm{m}(\mathrm{t})$ and successive difference between $\mathrm{m}(\mathrm{t})$ 's. of HLD. Table 3 shows the time between failures (cumulative) in hours, corresponding $\mathrm{m}(\mathrm{t})$ and successive difference between $\mathrm{m}(\mathrm{t})$ 's. of Exponential. 
Table 2- Successive difference of mean value function $(\mathrm{m}(\mathrm{t}))$ for HLD

\begin{tabular}{|c|c|c|r|r|r|r|r|}
\hline $\begin{array}{c}\text { Failure } \\
\text { number }\end{array}$ & $\begin{array}{c}\text { Time } \\
\text { between } \\
\text { Failure (hrs) } \\
\text { (cumulative) }\end{array}$ & $\mathbf{m}(\mathbf{t})$ & $\begin{array}{c}\text { Successive } \\
\text { Difference of m(t) }\end{array}$ & $\begin{array}{c}\text { Failure } \\
\text { number }\end{array}$ & $\begin{array}{c}\text { Time } \\
\text { between } \\
\text { Failure (hrs) } \\
\text { cumulative) }\end{array}$ & $\begin{array}{c}\text { Successive } \\
\text { Difference of } \\
\mathbf{m}(\mathbf{t})\end{array}$ \\
\hline 1 & 30.02 & 2.029923497 & 0.097077791 & 16 & 151.78 & 9.923046372 & 1.537552672 \\
\hline 2 & 31.46 & 2.127001289 & 1.508322141 & 17 & 177.5 & 11.46059904 & 0.163193461 \\
\hline 3 & 53.93 & 3.63532343 & 0.090815888 & 18 & 180.29 & 11.62379251 & 0.111880954 \\
\hline 4 & 55.29 & 3.726139318 & 0.228756749 & 19 & 182.21 & 11.73567346 & 0.239476794 \\
\hline 5 & 58.72 & 3.954896066 & 0.876131706 & 20 & 186.34 & 11.97515025 & 3.81959287 \\
\hline 6 & 71.92 & 4.831027772 & 0.339809004 & 21 & 256.81 & 15.79474312 & 0.844951713 \\
\hline 7 & 77.07 & 5.170836776 & 0.251905868 & 22 & 273.88 & 16.63969484 & 0.192817725 \\
\hline 8 & 80.9 & 5.422742644 & 1.367531191 & 23 & 277.87 & 16.83251256 & 6.758258675 \\
\hline 9 & 101.9 & 6.790273835 & 0.831570421 & 24 & 453.93 & 23.59077124 & 2.071137895 \\
\hline 10 & 114.87 & 7.621844256 & 0.029928296 & 25 & 535 & 25.66190913 & 0.050033654 \\
\hline 11 & 115.34 & 7.651772553 & 0.395282189 & 26 & 537.27 & 25.71194279 & 0.333705373 \\
\hline 12 & 121.57 & 8.047054742 & 0.214578039 & 27 & 552.9 & 26.04564816 & 2.021062108 \\
\hline 13 & 124.97 & 8.26163278 & 0.57016458 & 28 & 673.68 & 28.06671027 & 0.382797878 \\
\hline 14 & 134.07 & 8.831797361 & 0.135664868 & 29 & 704.49 & 28.44950815 & 0.373798464 \\
\hline 15 & 136.25 & 8.967462229 & 0.955584143 & 30 & 738.68 & 28.82330661 & - \\
\hline
\end{tabular}

Table-3: Successive Difference of mean value function $\mathbf{m}(\mathrm{t})$ for Exponential

\begin{tabular}{|c|c|c|c|c|c|c|c|}
\hline $\begin{array}{c}\text { Failure } \\
\text { No }\end{array}$ & $\begin{array}{c}\text { Cumulative } \\
\text { failures }\end{array}$ & $\mathrm{m}(\mathrm{t})$ & $\begin{array}{c}\mathrm{m}(\mathrm{t}) \text { Successive } \\
\text { Difference }\end{array}$ & $\begin{array}{c}\text { Failure } \\
\text { No }\end{array}$ & $\begin{array}{c}\text { Cumulative } \\
\text { failures }\end{array}$ & $\mathrm{m}(\mathrm{t})$ & $\begin{array}{c}\mathrm{m}(\mathrm{t}) \\
\text { Successive } \\
\text { Difference }\end{array}$ \\
\hline 1 & 30.02 & 3.745007495 & 0.168687503 & 16 & 151.78 & 15.09281062 & 1.773292339 \\
\hline 2 & 31.46 & 3.913694999 & 2.511282936 & 17 & 177.5 & 16.86610295 & 0.181718724 \\
\hline 3 & 53.93 & 6.424977934 & 0.1449395 & 18 & 180.29 & 17.04782168 & 0.123892025 \\
\hline 4 & 55.29 & 6.569917434 & 0.362096035 & 19 & 182.21 & 17.1717137 & 0.263324295 \\
\hline 5 & 58.72 & 6.932013469 & 1.348473204 & 20 & 186.34 & 17.435038 & 3.888381284 \\
\hline 6 & 71.92 & 8.280486673 & 0.507278516 & 21 & 256.81 & 21.32341928 & 0.789509245 \\
\hline 7 & 77.07 & 8.787765189 & 0.370602904 & 22 & 273.88 & 22.11292853 & 0.176969998 \\
\hline 8 & 80.9 & 9.158368093 & 1.935032465 & 23 & 277.87 & 22.28989853 & 5.577616276 \\
\hline 9 & 101.9 & 11.09340056 & 1.11713536 & 24 & 453.93 & 27.8675148 & 1.518886819 \\
\hline 10 & 114.87 & 12.21053592 & 0.039414228 & 25 & 535 & 29.38640162 & 0.03590267 \\
\hline 11 & 115.34 & 12.24995015 & 0.515572704 & 26 & 537.27 & 29.42230429 & 0.238631489 \\
\hline 12 & 121.57 & 12.76552285 & 0.275243684 & 27 & 552.9 & 29.66093578 & 1.420599455 \\
\hline 13 & 124.96 & 13.04076653 & 0.72160932 & 28 & 673.68 & 31.08153524 & 0.266001157 \\
\hline 14 & 134.07 & 13.76237585 & 0.168851459 & 29 & 704.49 & 31.34753639 & 0.259556189 \\
\hline 15 & 136.25 & 13.93122731 & 1.161583304 & 30 & 738.68 & 31.60709258 & \\
\hline
\end{tabular}

\subsection{Control Limits}

Using values of ' $\hat{a}$ ' and ' $\hat{b}$ shown in table- 2 we can compute $m(t)$. Equating the $p d f$ of $\mathrm{m}(t)$ to 0.00135 , 0.99865 , and 0.5 and the respective control limits are given by

$T_{U}=\left(1-e^{-b t}\right)=0.99865$
$T_{C}=\left(1-e^{-b t}\right)=0.5$

$T_{L}=\left(1-e^{-b t}\right)=0.00135$

These limits are convert at $m\left(t_{u}\right), m\left(t_{C}\right)$ and $m\left(t_{L}\right)$ are given by

\begin{tabular}{|c|c|c|c|}
\hline Name of the Distribution & $m\left(T_{U}\right)$ & $m\left(T_{C}\right)$ & $m\left(T_{L}\right)$ \\
\hline Exponential & 33.3512569 & 16.6981710 & 0.04508506 \\
\hline Half Logistic & 31.23462967 & 15.63842905 & 0.042223764 \\
\hline
\end{tabular}

\subsection{Control Chart}

Statistical Process Control (SPC) is a statistical approach that determines whether a process is stable or not by discriminating between common cause variation and assignable cause variation. A process is said to be "stable" or "under control", if it is affected by common causes only. The control chart evaluates process performance by comparing it with a measure of its central tendency, an upper and lower limit of admissible performance variations. The interest of using SPC in software is highlighted by many contributions in literature: applications in inspections and review [5, 6, 7, 24], testing [2, 3, 9], maintenance [22, 23], personal software process [23], and other topics [1]. We named the control chart as Failures Control Chart for HLD, Mean Value Control Chart for Exponential in this paper. The said control charts help to assess the software failure phenomena on the basis of the given inter- failure time data.

The values of $m(t)$ at $T_{c}, T_{u}, T_{L}$ and at the given 30 interfailure times are calculated. Then the $\mathrm{m}(\mathrm{t})$ 's are taken, which leads to 29 values. The graph with the said interfailure times 1 to 30 on X-axis, the 29 values of $\mathrm{m}(\mathrm{t})$ 's on $\mathrm{Y}$-axis, and the 3 control lines parallel to $\mathrm{X}$-axis at $\mathrm{m}\left(\mathrm{T}_{\mathrm{L}}\right)$, $\mathrm{m}\left(\mathrm{T}_{\mathrm{U}}\right), \mathrm{m}\left(\mathrm{T}_{\mathrm{C}}\right)$ respectively constitutes failures control chart and mean value chart to assess the software failure phenomena on the basis of the given inter-failures time data. 


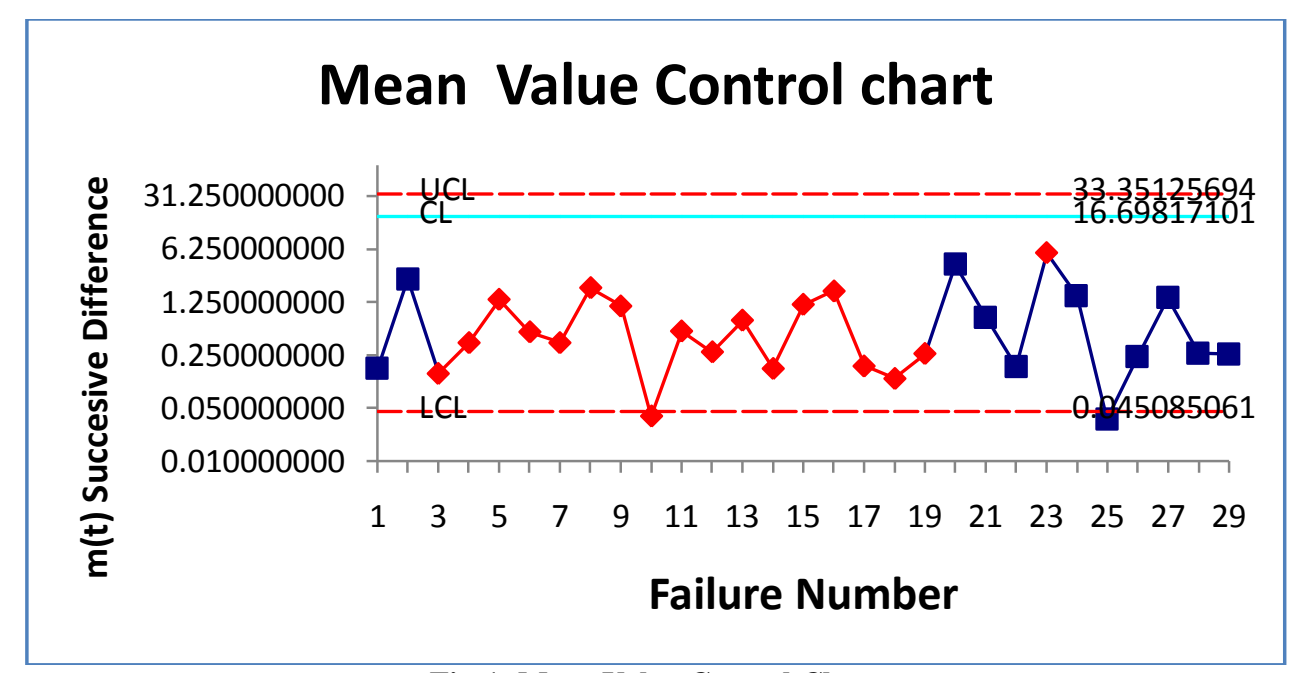

Fig-1: Mean Value Control Chart

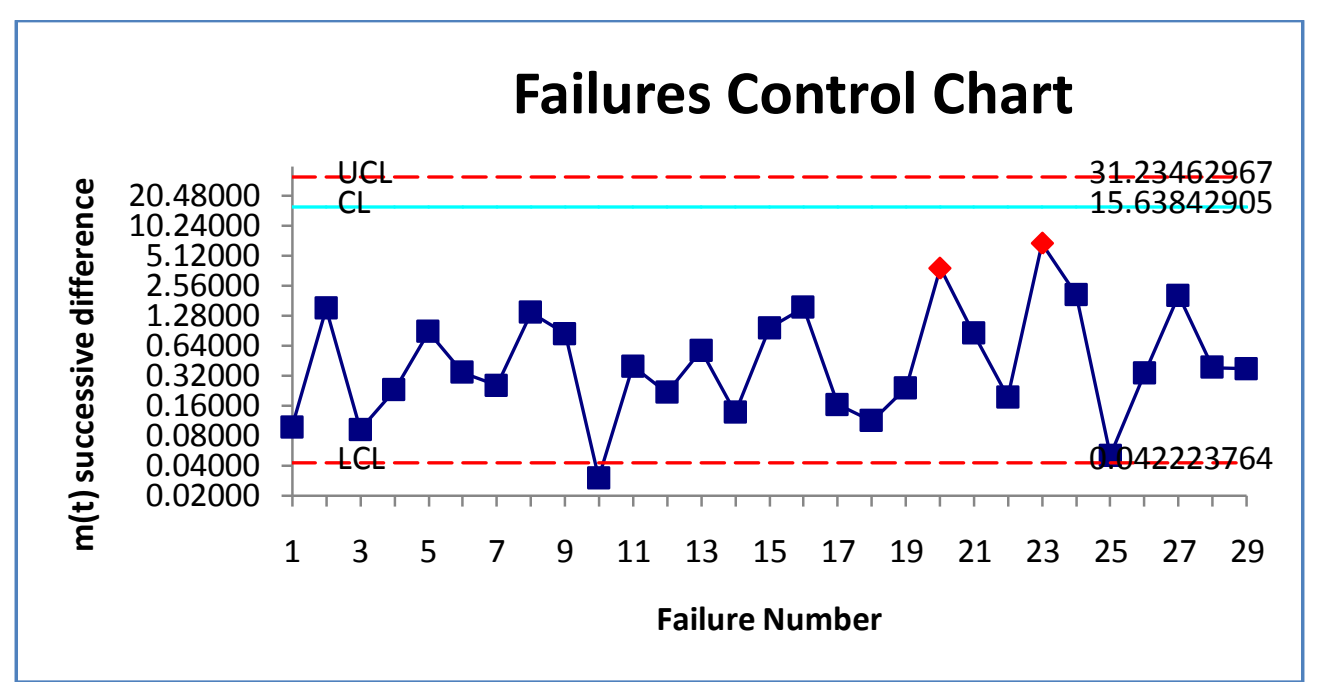

Fig-2: Failure Control Chart

\section{CONCLUSION}

The failures control chart (Fig-1) and the mean value control chart (Fig-2) exemplifies that, the first out - of control situation is noticed at the $10^{\text {th }}$ failure with the corresponding successive difference of $m(t)$ falling below the LCL. The two control charts using exponential and HLD shows the similar results Hence it is claimed that the failures control chart and mean value chart detects out - of control in a positive way. Therefore, earlier detections are possible in failures control chart and mean value chart. Since both control mechanisms are making the detection at the same point, either mechanism based on Exponential Distribution [1] or Half Logistic Distribution [2] is preferable.

\section{REFERENCES}

Card D., (1994), Statistical Process Control for Software, IEEE Software, May, 95-97.

[1.] Card D., Berg R.A., (1989), An Industrial Engineering Approach to Software Development. J. Systems and Software, 10, 159-168.

[2.] Card D., Glass R.L., (1990), Measuring Software Design Quality, Prentice Hall

[3.] Cohen, A.C. and Whitten, B. (1980). Modified moment and maximum likelihood estimators for parameters of the three-parameter gamma distribution. Commun.Statist. -Simu. Comp. 11, 197\{216.

[4.] Ebenau R.G., (1994), Predictive Quality Control with Software Inspections, Crosstalk, June.

[5.] Florac W.A., Carleton A.D., Bernard J.R., (2000), Statistical Process Control: Analyzing a Space Shuttle Onboard Software Process, IEEE Software, July/August.

[6.] Florence A., (2001), CMM Level 4 Quantitative Analysis and Defect Prevention, Crosstalk, Feb. 2001.

[7.] G. Srinivasa Rao, R. R. L. Kantam and K. Rosaiah, Reliability estimation in log-logistic distribution from censored samples, ProbStat Forum, Volume 02, July 2009, Pages 52-67
[8.] Jalote P., (1999), CMM in Practice: Processes for Executing Software Projects at Infosys, AddisonWesley.

[9.] K. Rosaiah, R. R. L. Kantam, G. Srinivasa Rao and P. Mallikharjuna Rao, ESTIMATION IN TRUNCATED TYPE-I GENERALIZED LOGISTIC DISTRIBUTION, Int. J. Agricult. Stat. Sci., Vol. 5, No. 2, pp. 317-325, 2009

[10.]M.Xie, T.N. Goh, P. Rajan; Some effective control chart procedures for reliability monitoring; Elsevier science Ltd, Reliability Engineering and system safety 77(2002) 143- 150

[11.]Mehrotra, K.G. and Nanda, P. (1974). Unbiased estimation of parameters by order Statistics in the case of censored samples. Biometrika, 61, 601\{606.

[12.] Mutsumi Komuro; Experiences of Applying SPC Techniques to software development processes; 2006 ACM 1-59593-085-x/06/0005.

[13.]Paulk M.C., (2001), Applying SPC to the Personal Software Process, Proceedings of the $10^{\text {th }}$ International. Conference on Software Quality, October

[14.]Persson, T and Rootzen, H. (1977). Simple highly efficient estimators for a Type I censored normal sample. Biometrika, 64, $123\{128$.

[15.]R Satya Prasad, Bandla Sreenivasa Rao, Dr. R.R. L Kantham, Monitoring Software Reliability using Statistical Process Control: An MMLE Approach, International Journal of Computer Science \& Information Technology (IJCSIT) Vol 3, No 5, Oct 2011

[16.] R Satya Prasad, K Ramchand H Rao Rao, Dr. R.R. L Kantham, Software Reliability Measuring using Modified Maximum Likelihood Estimation and SPC, International Journal of Computer Applications (0975 - 8887) Volume 21-No.7. May 2011

[17.]Tiku, M.L. (1967). Estimating the mean and standard deviation from a censored normal sample. Bionetrika, 54, 155\{165. 
[18.]Tiku, M.L. (1988). Modified maximum likelihood estimator for the bivariate normal Commun. Statist.-Theor. Meth., 17, 893 910.

[19.]Tiku, M.L. and Suresh, R.P. (1992). A new method of estimation for location and scale parameters. J. Statist. Plann. \& Inf. 30, 281-292, North- Holland.

[20.]Tiku, M.L., Wong, W. K., Vaughan, D.C. and Bian, G. (2000). Time series models in nonnormal situations: symmetric innovations. Journal of Time Series Analysis, 21, 571\{596.
[21.]Weller E., (1995), Applying Statistical Process Control to Software Maintenance. Proc. Applications of Software Measurement

[22.]Weller E., (2000), Applying Quantitative Methods to Software Maintenance, ASQ Software Quality Professional, 3 (1).

[23.]Weller E., (2000), Practical Applications of Statistical Process Control, IEEE Software, May/June, 48-55 